Article

\title{
Non-Invasive Morphological Characterization of Rice Leaf Bulliform and Aerenchyma Cellular Regions Using Low Coherence Interferometry
}

\author{
Hyeree Kim ${ }^{1, \dagger}{ }^{,}$XiaoXuan Du ${ }^{2,+}$, Sungwook Kim ${ }^{1}$, Pilun Kim ${ }^{3}$, Ruchire Eranga Wijesinghe ${ }^{4}$, \\ Byoung-Ju Yun ${ }^{1, *} \mathbb{\infty}$, Kyung-Min Kim ${ }^{2, *} \mathbb{D}$, Mansik Jeon ${ }^{1, *}$ and Jeehyun $\mathrm{Kim}^{1}$ \\ 1 School of Electronics Engineering, College of IT Engineering, Kyungpook National University, 80, Daehak-ro, \\ Buk-gu, Daegu 41566, Korea; hleeworld@gmail.com (H.K.); seong2844@naver.com (S.K.); \\ jeehk@knu.ac.kr (J.K.) \\ 2 Division of plant Biosciences, School of Applied Biosciences, College of Agriculture \& Life Science, \\ Kyungpook National University, Daegu 41566, Korea; haobingshuaike@hotmail.com \\ 3 Institute of Biomedical Engineering, School of Medicine, Kyungpook National University, 680, \\ Guk-chaebosang-ro, Dong-gu, Daegu 41944, Korea; pukim@knu.ac.kr \\ 4 Department of Biomedical Engineering, College of Engineering, Kyungil University, 50, Gamasil-gil, \\ Hayang-eup, Gyeongsan-si, Gyeongsangbuk-do 38428, Korea; eranga@kiu.kr \\ * Correspondence: bjisyun@ee.knu.ac.kr (B.-J.Y.); kkm@knu.ac.kr (K.-M.K.); msjeon@knu.ac.kr (M.J.); \\ Tel.: +82-53-950-7846 (M.J.) \\ + These authors contributed equally to this work.
}

Received: 23 March 2019; Accepted: 20 May 2019; Published: 22 May 2019

\begin{abstract}
Non-invasive investigation of rice leaf specimens to characterize the morphological formation and particular structural information that is beneficial for agricultural perspective was demonstrated using a low coherence interferometric method called swept source optical coherence tomography (SS-OCT). The acquired results non-invasively revealed morphological properties of rice leaf, such as bulliform cells; aerenchyma, parenchyma, and collenchyma layer; and vascular bundle. Beside aforementioned morphologic characteristics, several leaf characteristics associated with cytological mechanisms of leaf rolling (leaf inclination) were examined for the pre-identification of inevitable necrosis and atrophy of leaf tissues by evaluating acute angle information, such as angular characteristics of the external bi-directional angles between the lower epidermis layer and lower mid-vein, and internal angle of lower mid-vein. To further assist the pre-identification, acquired cross-sections were employed to enumerate the small veins of each leaf specimen. Since mutants enlarge leaf angles due to increased cell division in the adaxial epidermis, healthy and abnormal leaf specimens were morphologically and quantitatively compared. Therefore, the results of the method can be used in agriculture, and SS-OCT shows potential as a rigorous investigation method for selecting mutant infected rice leaf specimens rapidly and non-destructively compared to destructive and time consuming gold-standard methods with a lack of precision.
\end{abstract}

Keywords: swept source optical coherence tomography (SS-OCT); rice leaf; biological tomographic imaging; morphological; Bulliform cellular region; Aerenchyma cellular region

\section{Introduction}

Rice is a highly productive crop per unit area and one of the major agricultural products in the world, which has a potential impact on the world economy [1,2]. Since rice is widely produced in many countries, descriptive understanding of the cellular regions, such as bulliform cells, aerenchyma cells, mid-vein and collenchyma cells are essential for increased yields. Bulliform cells are highly vacuolated 
cells, which are located on the adaxial epidermis between the vein ribs of the rice leaf blade $[3,4]$. Bulliform cells control leaf rolling (occuring due to certain mutations) and maintain the biological nature and structure of leaf [5]. The mid-vein of the leaf specimen consists of few aerenchyma, which are separated by parenchyma cell bands. Aerenchyma are composed of airy compartments that allow an exchange of gases between the leaves and other tissues [6,7]. Collenchyma cells consist of irregularly thick cell walls that provide support and structure to the leaf specimen. Figure 1 depicts a laboratory designed schematic diagram describing aforementioned rice leaf structural formation, emphasizing morphological differences.

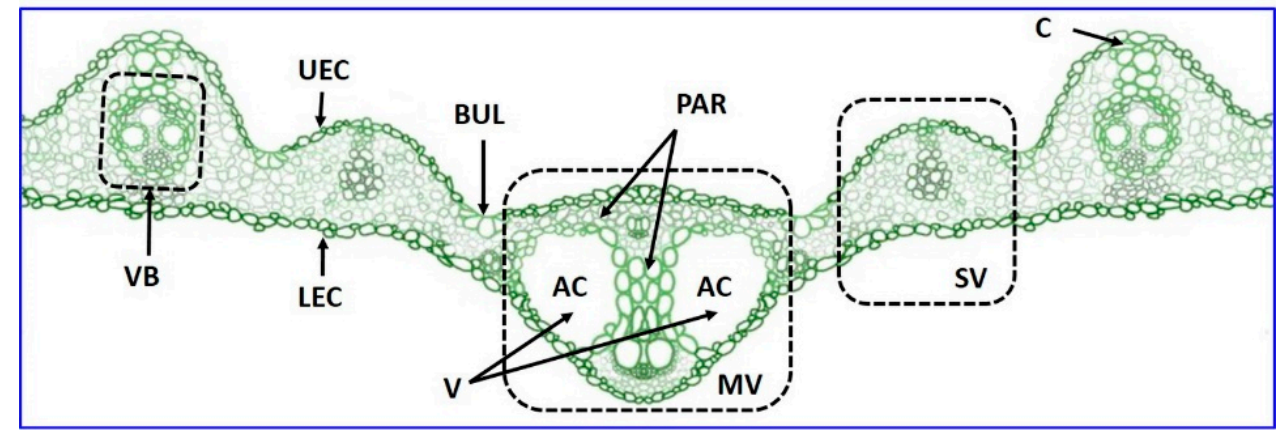

Figure 1. The schematic diagram of rice leaf structural formation. Note the use of the following acronyms in the figure: AC: aerenchyma, BUL: bulliform cells, C: collenchyma, L: lower epidermis cells, MV: mid-vein, PAR: parenchyma, SV: small vein, U: upper epidermis cells, V: vacuum regions, VB: vascular bundle.

The yield of rice has been increased through the improvement of species, development of fertilizers, and development of farming tools [8]. However, genetically mutated disease pathogens and unexpected climate changes have reduced the annual yield [9]. Numerous studies confirmed that mutants change the number, size, and pattern of small veins, bulliform cells, parenchyma cells, and mesophyll cells, as well as vascular bundles, which leads to leaf rolling. Further, these mutations subsequently alter the leaf angle at later stages, such that a lower level of leaf area/unit land degrades the high photosynthesis rate [10-12].

To overcome the aforementioned drawbacks and disease related obstacles, numerous research groups have put enormous effort into gene modification and disease control [13-15]. Histological analysis and polymerase chain reaction (PCR) techniques have been frequently performed to identify the infected leaf specimens and observe morphological sections [16-19]. Destructive histological analysis enables the observation of dyed cellular and tissue regions using an optical microscope or an electron microscope [18]. However, chemically immobilizing cells and tissues with formaldehyde or other chemicals can deteriorate cells and tissues very easily. PCR is a destructive molecular biological technique, which is widely used in agriculture to diagnose plant disease by detecting the DNA of the pathogen. Nevertheless, the amplification of contaminated RNA leads to the generation of plenty of errors during the experiment. As non-destructive inspection solutions for plant diseases, visual inspection, magnetic resonance imaging (MRI) [20-22], X-ray [23], positron emission tomography (PET) [22,24], confocal microscopy [25], and fluorescence spectroscopy have been utilized to overcome the limitations of histological and PCR methods. Three dimensional (3D) optical profiler is an alternative non-contact method, which can be used to obtain two-dimensional (2D) and 3D views of the leaf surface along with the optical profile graphs determining epidermal cellular height [26]. However, the analysis is limited to surface, while inadequate spatial resolution and lack of cross-sectional information hinder the extensive applicability in agriculture. Therefore, the aforementioned lack of resolution to identify microstructures and infected regions, high cost, and long acquisition time encouraged the researchers to seek a high-resolution, non-destructive, and real-time rapid inspection technique as an optimized solution. 
Optical coherence tomography (OCT) is a purely non-destructive biomedical imaging technique capable of generating real-time high-resolution tomographic and volumetric images. Moreover, OCT has been fundamentally applied in ophthalmology [27,28], dentistry [29,30], otolaryngology [31] and industrial defect examinations [32,33]. During the last decade, OCT has been employed for various agricultural applications, since it can overcome the disadvantages of existing agricultural techniques. The potential applicability of OCT for agriculture was demonstrated at numerous attempts by our group conducting studies for quality inspection of fruit [34,35], seed [36,37], and leaf specimens [38-41], and seed growth [42-44] speed measurements recently.

In this paper, swept source optical coherence tomography (SS-OCT) was used for the morphological characterization of particular cellular regions of rice leaf specimens non-invasively. The acquired qualitative assessments deliver a fundamental understanding regarding the internal structural properties of rice leaf specimens, which are considered important regions of interest from an agricultural perspective. To further confirm the high-resolution and quantitative assessments of the imaging technique, acquired images were utilized to enumerate the small veins, examine leaf layer thickness, and measure leaf angular measurements including the external bi-directional angles between the lower epidermis layer and lower mid-vein, and the internal angle of lower mid-vein; these are important parameters for the pre-identification of mutations.

\section{Materials and Methods}

\subsection{System Configuration of SS-OCT}

The rice leaf specimens were imaged using a commercial SS-OCT system (Thorlabs. Inc, OCS1310V1 OCT). The OCT system uses a MEMS-VCSEL sweep source laser. Figure 2 depicts the system configuration of the utilized SS-OCT system. The OCT system operates at a center wavelength of $1300 \mathrm{~nm} \pm 15 \mathrm{~nm}$ and average output power of $20 \mathrm{~mW}$ with a broadband tuning range of more than $97 \mathrm{~nm}$. The swept laser source used in this OCT system has A-scan line sweep rate of $100 \mathrm{kHz}$. A numerical aperture of the objective scan lens was 0.11 , and the sensitivity of the OCT system was $105 \mathrm{~dB}$. The interference signal of the interferometer is received from the detector and sent to the DAQ. The interferogram is sampled with equal temporal intervals, where the data set is evenly distributed in time domain but not necessarily in the frequency or wavenumber domain. Unless the frequency/wavenumber is tuned linearly with time, direct FFT on this data set, which is non-equidistantly distributed in wavenumber domain leads to significant transform errors. Hence, each pair of OCT signal and clock signal were examined by the nearest neighbor check algorithm for crossing points, which can be performed according to methods reported in $[45,46]$. Next, the OCT data set was indexed by referencing these searched points prior to FFT process [47]. The axial resolution of the system is $12 \mu \mathrm{m}$ in tissue and $16 \mu \mathrm{m}$ in air, and the lateral resolution including the objective lens (Thorlabs. Inc, LSM03) is $25 \mu \mathrm{m}$ in tissue and $33 \mu \mathrm{m}$ in air at focus. The inset images of Figure 2 illustrate the horizontal and vertical scanning directions of leaf specimens. The maximum field of view of the OCT system is $10 \times 10 \times 3 \mathrm{~mm}$. The detailed configuration of the system is reported elsewhere [48].

\subsection{Preparation of Rice Leaf Specimens}

The experimental specimens were provided by the College of Agriculture and Life Sciences of Kyungpook National University. The specimens were collected from the CNDH (Cheongcheong/ Nagdong doubled haploid lines) population. The collection time was 40 days after the population transplantation. The specimens were fundamentally used for physiological studies, morphological studies, and extraction of DNA and RNA. All specimens were stored in $-80^{\circ} \mathrm{C}$ degrees immediately after the collection to avoid the characteristic changes of specimens. In general, a low temperature $\left(-80{ }^{\circ} \mathrm{C}\right)$ is required for the specimen storage to provide rapid cooling and frozen conditions to freeze cell gaps, avoiding particular changes in cells and DNA structures. In the case of frozen conditions, the humidity of the cells is refrigerated before being changed, and it is returned to its original form once 
the specimens are kept in room temperature. To further maintain the biological freshness in order to overcome the shortcomings of dehydration, all the experimented samples were placed in water while doing the experiment. To minimize leaf damage, image acquisition was performed within $5 \mathrm{~min}$ after the specimens were removed from water. The photographs in Figure 3 depict the representative front and rear appearance of randomly chosen apparently healthy six rice leaf specimens. The 2D-OCT scanning of the specimens was performed at the mid-vein located in the center of lateral axis. The blue color markers indicated on each leaf specimen correspond to the exact location, where the 2D-OCT images were extracted and the initiating position of 3D-OCT scans. In the experimental procedure, the primary inspection attempt was conducted using randomly chosen apparently healthy leaf specimens with healthy or partially healthy conditions to confirm the potential of functionality of the proposed experimental procedure. The secondary experimental attempt was conducted using five healthy specimens, which were later inoculated with Xan-grading bacterial leaf blight disease to investigate the feasibility of the method.

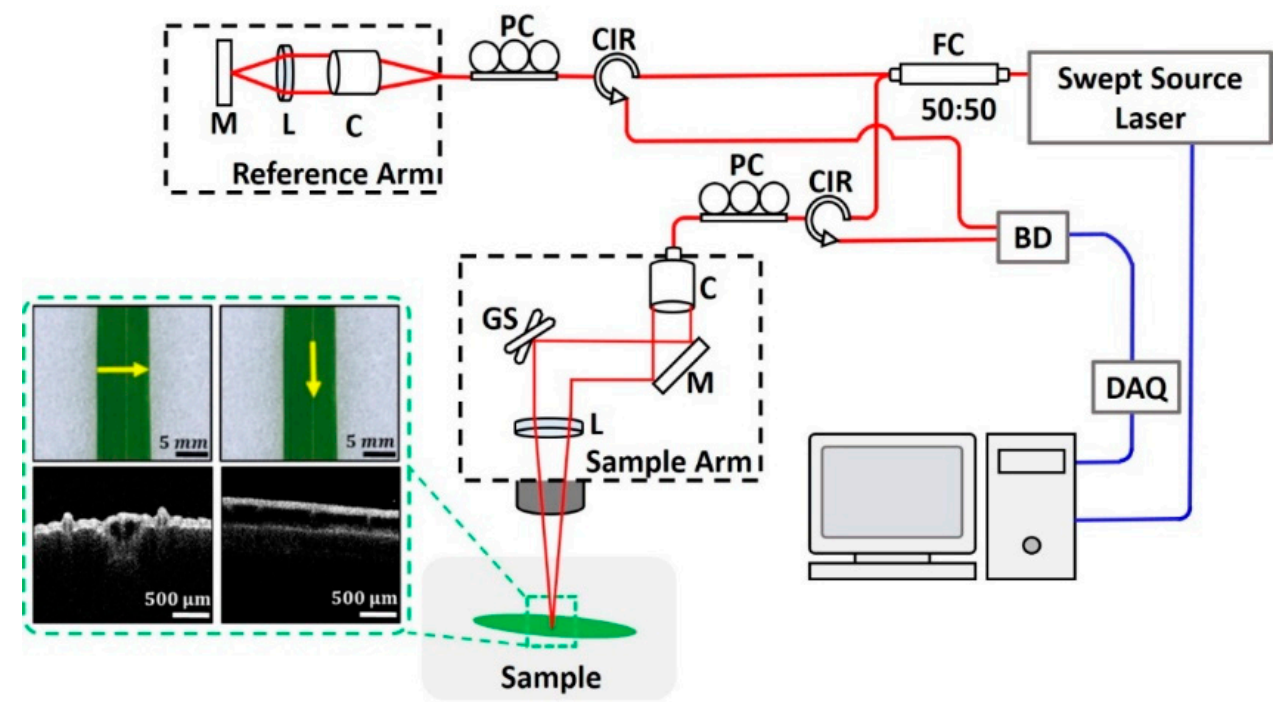

Figure 2. The schematic of the swept source optical coherence tomography (SS-OCT) optical screening system. Note the use of the following acronyms in the figure: BD: balanced detector, C: collimator, CIR: circulator, DAQ: data acquisition, FC: fiber coupler, GS: galvano scanner, L: lens, M: mirror, PC: polarization controller, SS: swept laser source. The green color-dotted square box is horizontal and vertical scanning direction and corresponding B-scan images.

\begin{tabular}{|c|c|c|c|c|c|c|}
\hline & $\begin{array}{c}\text { Specimen } \\
\# 1\end{array}$ & $\begin{array}{c}\text { Specimen } \\
\# 2\end{array}$ & $\begin{array}{c}\text { Specimen } \\
\# 3\end{array}$ & $\begin{array}{c}\text { Specimen } \\
\# 4\end{array}$ & $\begin{array}{c}\text { Specimen } \\
\# 5\end{array}$ & $\begin{array}{c}\text { Specimen } \\
\# 6\end{array}$ \\
\hline Front & 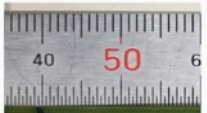 & 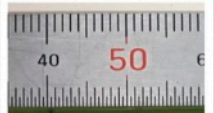 & 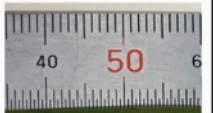 & 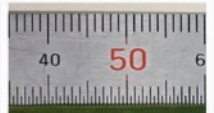 & 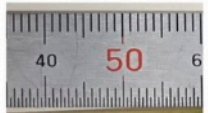 & 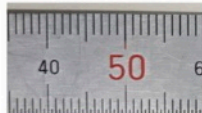 \\
\hline Rear & 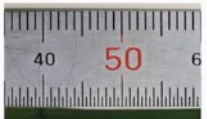 & 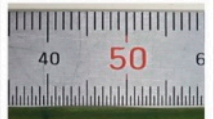 & 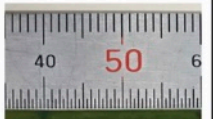 & 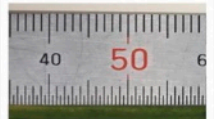 & 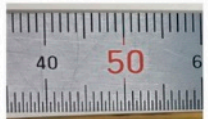 & 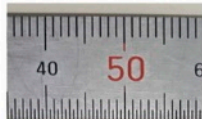 \\
\hline
\end{tabular}

Figure 3. Photographs for six rice leaf specimens. 


\section{Results}

\subsection{Bi-Directional Investigation of Rice Leaf Specimen}

Figure 4a depicts representative arbitrarily set front surface along with an arbitrarily set rear surface (Figure $4 \mathrm{~b}$ ) of rice leaf specimen. The external dimensions of representative leaf specimen were $8.2 \mathrm{~mm}$ in the horizontal direction (width) and $75.6 \mathrm{~mm}$ in the vertical direction (length). The red dotted lines in the center of Figure 4a,b indicate the scanned position and direction of both front and rear sides of leaf specimen. A constant scan range of $10 \mathrm{~mm}$ was maintained for all the specimens. Figure $4 \mathrm{c}, \mathrm{d}$ illustrate cross-sectional OCT images acquired from the corresponding regions of interest of Figure 4a,b respectively. The cellular formations, such as bulliform cells (epidermal cells) and aerenchyma cellular regions, were precisely confirmed non-destructively through the acquired cross-sections. Aerenchyma is the structure that allows the flow of gases, such as oxygen and carbon dioxide, to pass through or be stored, and also plays a role in discharging methane gas. Therefore, this structural observation is important, since they are involved in plant growth. As emphasized in Figure 4, bulliform cells are located between two vascular bundle ridges. Further, the cross-sections depict morphological formation of vascular bundles along with small veins, the vicinity of the mid-vein, internal vacuum regions, and cellular regions (aerenchyma and parenchyma cells), which can be beneficial to confirm mutations at an early stage.
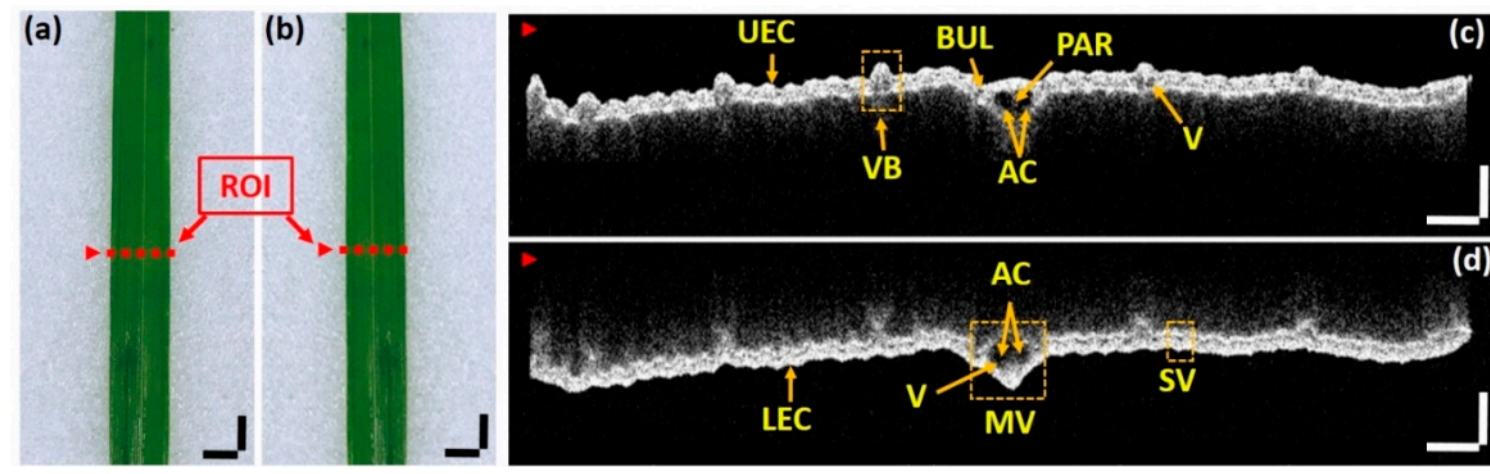

(c)

Figure 4. Comparison of two-dimensional SS-OCT images of the front and rear surface of the rice leaf specimens: $(\mathbf{a}, \mathbf{b})$ shows the front and rear surface of the rice leaf specimens. The red dotted line indicates the region of interest along with the scanning direction. The sub-figures (c,d) exhibit two-dimensional SS-OCT images of $(\mathbf{a}, \mathbf{b})$. Lateral and vertical scale bars: $500 \mu \mathrm{m}$. AC: Aerenchyma, BUL: Bulliform cells, LEC: lower epidermis cells, MV: mid-vein, PAR: parenchyma, SV: small vein, UEC: upper epidermis cells, V: vacuum region and VB: vascular bundle.

\subsection{Volumetric and Depth Dependent En-Face Visualization}

To gain a better understanding regarding volumetric structures of leaf specimens, three-dimensional scanning method of OCT was utilized. The depth dependent en-face visualizations were involved to confirm the consistency of the examined position in depth range through the obtained 3D rendered images. Figure $5 a, b$ illustrate the three dimensionally constructed front and rear surfaces of rice leaf specimen. Figure $5 \mathrm{c}-\mathrm{f}$ emphasizes the magnified visualizations of the regions of interest indicated with red square boxes on Figure $5 \mathrm{a}, \mathrm{b}$. Figure $5 \mathrm{~g}$, h represents the en-face visualizations taken at a depth of $50 \mu \mathrm{m}$ underneath the epidermal cell layer. The en-face representation exhibits the internal cellular patterns of mid-vein, aerenchyma, and bulliform cells with a high resolution confirming the potential applicability compared to existing inspection methods. Aerenchyma is a spongy tissue that forms spaces for air channels enabling exchange of gases $[49,50]$. As emphasized through en-face visualizations, the channels of air-filled cavities provide a low resistance internal pathway for the exchange of gases, such as oxygen and ethylene between the plant above the water and the submerged tissues. 

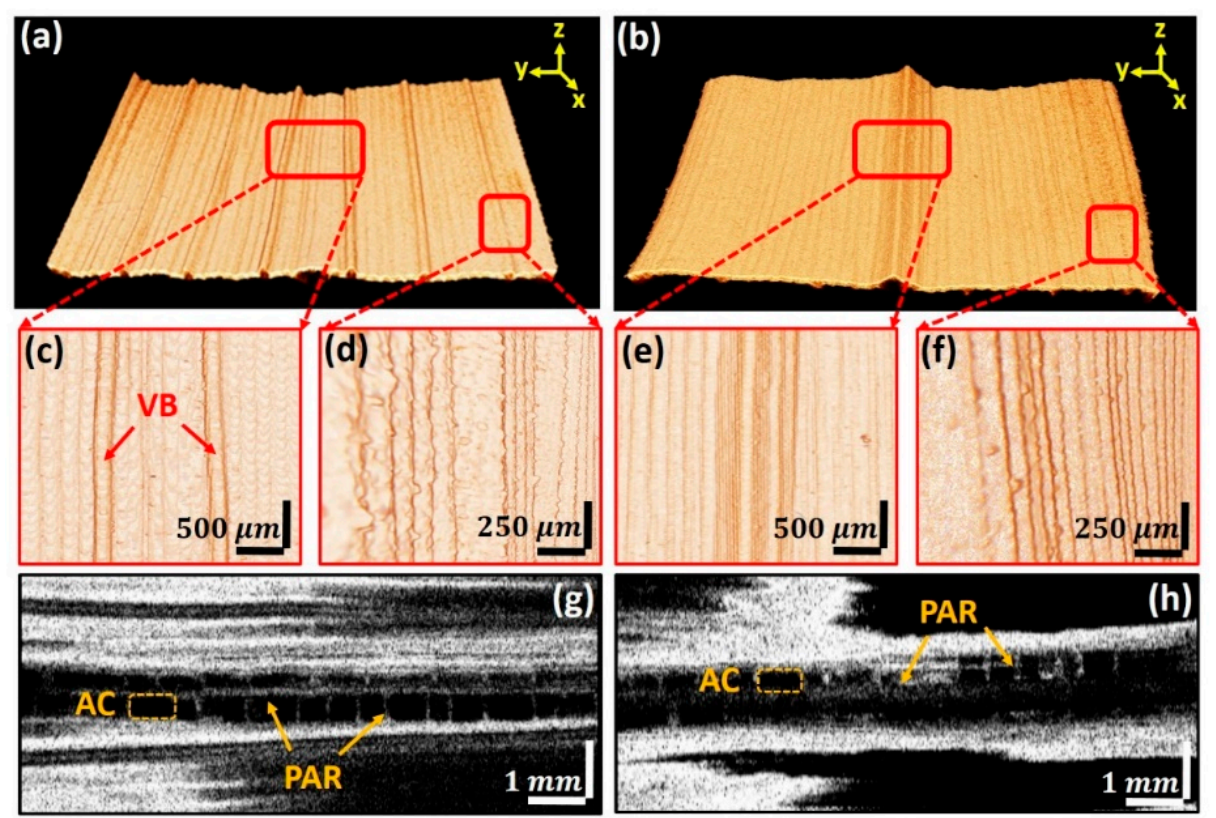

Figure 5. Reconstructed 3D-OCT images of rice leaf specimens. (a) Front surface of reconstructed 3D-OCT image, (b) rear surface of reconstructed 3D-OCT image. (c-f) Magnified image of the red square box indicated in $(\mathbf{a}, \mathbf{b}) ;(\mathbf{g}, \mathbf{h})$ are en-face images of mid-vein part of $(\mathbf{a}, \mathbf{b})$. AC: Aerenchyma, PAR: parenchyma and VB: vascular bundle. The en-face visualizations are rotated by 90 degrees in relation to the rest of the $3 \mathrm{D}$ renders.

\subsection{Quantitatively Enumerated Small Veins and Morphological Angular Measurements}

The number of small veins plays an important role in identifying the biological nature and quality of leaf specimens, since the cellular region can be decreased and destroyed as a result of dehydration and particular mutations. Since the structural dimension of a small vein is approximately between 200-250 $\mu \mathrm{m}$ in width and $80-100 \mu \mathrm{m}$ in height, the resolution of the utilized OCT system was sufficient to examine and enumerate small veins of the region of interest of each leaf specimen. The representative green colored vertical dashed lines indicated in Figure 6a provide a distinguishable visualization of small veins, which were enumerated five times and averaged for each leaf specimen. The angular measurements of the external bi-directional angles between the lower epidermis layer and lower mid-vein, and the internal angle of the lower mid-vein were measured using images obtained from the rear surface of leaf specimens. The angular measurements were performed using the open-source imageJ software [51]. Figure $6 \mathrm{~b}$ provides a graphical representation regarding the angular measurement procedure, where external bi-directional angles between lower epidermis layer and lower mid-vein (A1 and A3), and internal angle of lower mid-vein (A2). Figure 6c-e illustrates the aforementioned small vein enumerations, the thickness between lower epidermis and lower mid-vein boundary, and the angular assessments of each random leaf specimen. To enhance the precision of angular readings, the measurement procedure was repeated five times and averaged for each leaf specimen. The enumerated and averaged small veins, as well as the averaged mid-vein angular measurements, are arranged in the graph shown in Figure 6. Since the aforementioned quantifications were demonstrated to investigate the feasibility of OCT as a diagnostic tool for rice leaves, the acquired results reveal that the resolution of OCT is sufficient to enumerate small-veins and angular information, which can be extensively studied and involved as threshold parameters for future studies related to rice leaf specimens. 

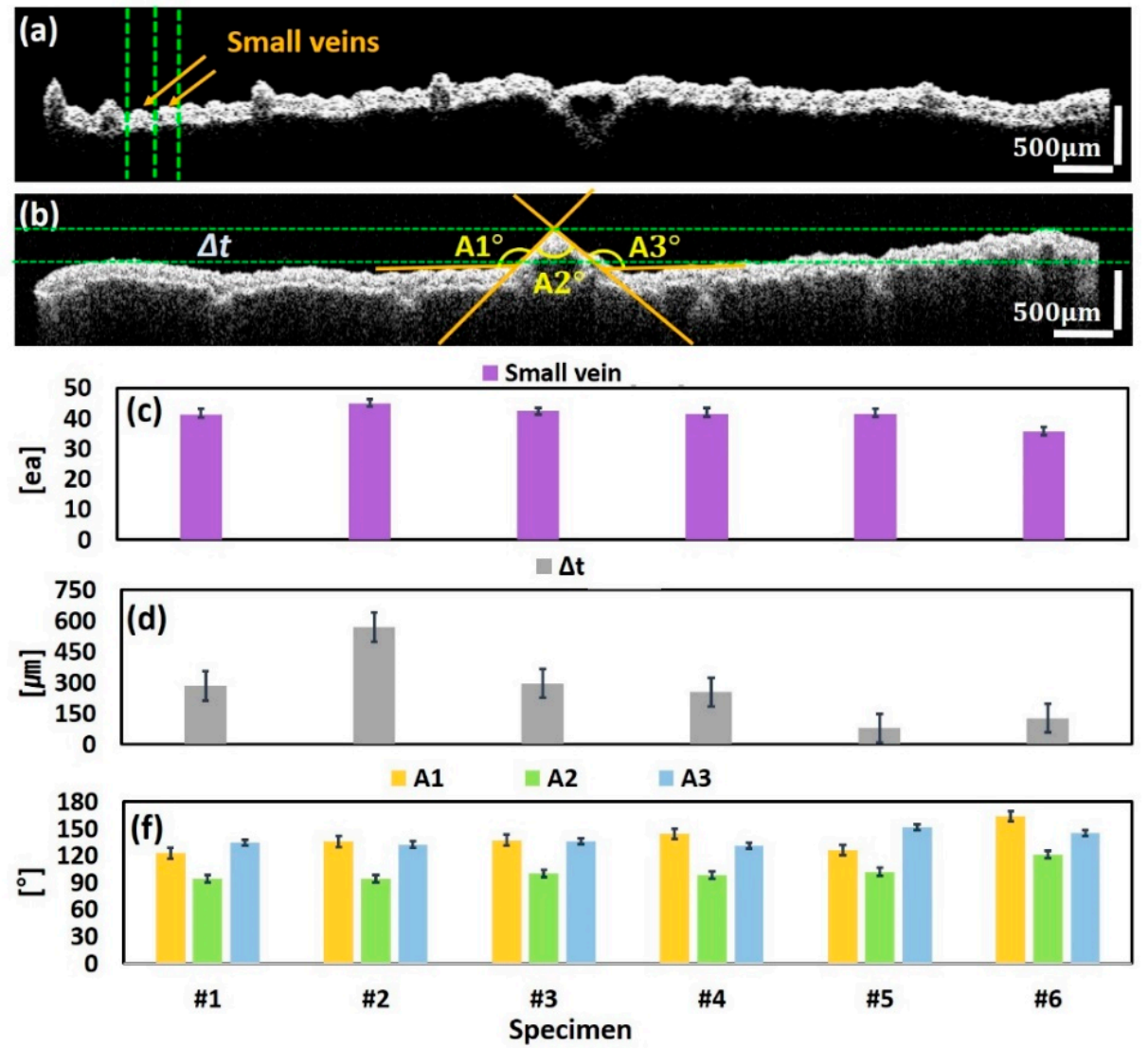

Figure 6. (a) Graphical description of the measurement procedure of small vein numbers. (b) The flipped 2D-OCT visualization acquired from the rear surface of the leaf specimen illustrating external bi-directional angles between lower epidermis layer and lower mid-vein (A1 and A3), and internal angle of lower mid-vein (A2). (c) Quantitative graphical representation of enumerated small vein information. (d) The thickness between lower epidermis layer and lower mid-vein $(\Delta t)$. (e) Quantitative graphical representation of angular information. (The error bars are the standard deviation).

\section{Discussion}

Here, we demonstrated an implementation of SS-OCT to confirm its applicability as an inspection tool in agriculture for the diagnosis of morphological mutations of rice leaf specimens. The competency of imaging the leaf morphology and the correlative quantifications suggest that the proposed method has various agricultural benefits that could be used to improve the pre-diagnosis process for rice leaf diseases. In fact, rice leaf morphology and quantifications related to small-vein and mid-vein have been studied previously by histological methods; however, these methods are destructive and time-consuming. The non-destructive SS-OCT imaging modality was used here for the first time and was found to have considerable merits over conventional methods. To the best of our knowledge, morphological identification, leaf rolling assessment and small-vein cellular enumeration analysis were performed destructively in agriculture and have not been studied descriptively using OCT technology [52-54]. Rice leaf consists of multiple tissue layers, while these tissues constitute the photosynthesis system and nutrient transport pipeline of rice. However, the destruction that occurs in leaf layers can lead to weakened photosynthesis, degrading the internal nutrient delivery system [55]. Moreover, when plants are infected, bacteria does not affect yield but results in poor quality grains and a high proportion of broken kernels. Since OCT is capable of providing vital morphological information non-destructively, the precision of the technique was further assessed through a comparison between healthy and abnormal leaf specimens. Therefore, to examine feasible applicability, rice leaf specimens were compared before (Figure 7a) and after (Figure 7b) the inoculation of Xan-grading bacterial leaf blight, which causes large-scale necrosis leading to thickness reduction and atrophy of leaf specimens. 

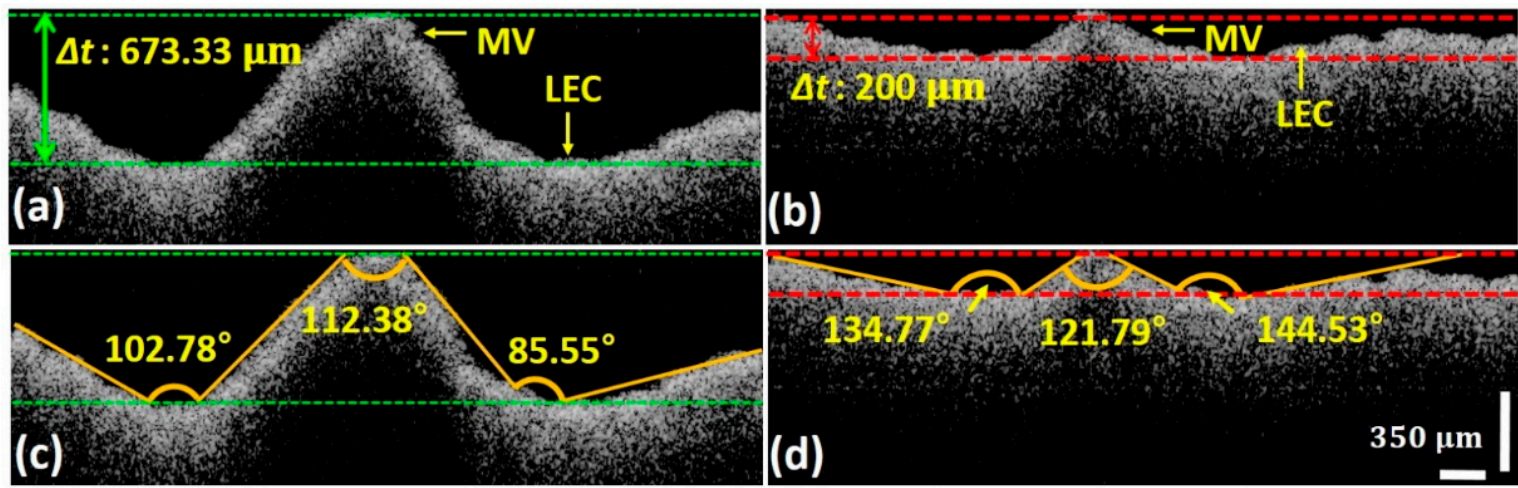

Figure 7. 2D-OCT image based thickness and mid-vein angular comparison between healthy and abnormal rice leaf specimens. (a,c) Healthy leaf specimen. (b,d) Abnormal specimen. $\Delta t$ : thickness between lower epidermis cells and lower mid-vein of both healthy and abnormal specimens. MV: mid-vein; LEC: lower epidermis cells.

The averaged reduction of thickness of leaf layers were examined and compared as shown in Figure 7. Here, the green and red color horizontal dotted lines in figures were considered the standard levels, where the upper range was fixed on lower mid-vein and the lower range was fixed on lower epidermis layer. All the standards were drawn and confirmed using imageJ software. Figure $7 \mathrm{a}, \mathrm{b}$, along with thickness measurements, provide a clearly identifiable thickness difference between healthy (before inoculation) and abnormal stages (after inoculation), verifying the potential merits of SS-OCT system as an inspection tool. Besides thickness assessments, the angular measurements, such as A1-A3 were examined to further confirm the precision, and the representative numerical results indicated on Figure $7 \mathrm{~d}$ revealed a significant angular expansion at the infected stage compared to the healthy stage, as shown in Figure 7c. Figure 7 depicts representative graphical illustrations with numerical assessments corresponding to thickness and angular analysis. To further confirm the demonstrated assessments, small vein enumerations, thickness assessments, and angular measurements of five leaf specimens were obtained at healthy and infected stages. To analyze each inspection parameter more precisely, a total of five measurements of each parameter were taken and averaged. The statistical values are emphasized in Tables 1-3. Table 1 provides a comparison of enumerated (average, minimum, maximum, and standard deviation) small vein information.

Table 2 compares the measured (average, minimum, maximum, and standard deviation) leaf thickness information, whereas Table 3 provides numerical information (average, minimum, maximum, and standard deviation) of three types of angular assessments as a comparison between healthy and infected leaf specimens.

Table 1. Numerically enumerated average, minimum, and maximum number of small veins compared between healthy and infected specimens, with standard deviations.

\begin{tabular}{cccccccccc}
\hline \multicolumn{1}{c}{ Small Vein (ea) } \\
\hline \multicolumn{1}{c}{ Healthy } & \multicolumn{7}{c}{ Infected } \\
\hline Number & Avg. & Min. & Max. & StdDev. & Number & Avg. & Min. & Max. & StdDev. \\
\hline 1 & 10 & 10 & 10 & 0 & 1 & 18 & 17 & 19 & 1 \\
2 & 9 & 8 & 9 & 1 & 2 & 12 & 12 & 12 & 0 \\
3 & 11 & 10 & 12 & 1 & 3 & 14 & 13 & 14 & 1 \\
4 & 10 & 9 & 10 & 1 & 4 & 18 & 17 & 18 & 1 \\
5 & 8 & 8 & 9 & 1 & 5 & 18 & 17 & 19 & 1 \\
\hline
\end{tabular}


Table 2. Numerically evaluated average, minimum, and maximum leaf layer thickness compared between healthy and infected specimens with standard deviations.

\begin{tabular}{cccccccccc}
\hline \multicolumn{7}{c}{ Healthy } & \multicolumn{7}{c}{ Thickness $(\mu \mathrm{m})$} \\
\hline Number & Avg. & Min. & Max. & StdDev. & Number & Avg. & Min. & Max. & StdDev. \\
\hline 1 & 597.1 & 586.9 & 602.7 & 5.6 & 1 & 211.5 & 198.7 & 219.3 & 7.2 \\
2 & 667.6 & 663.4 & 668.9 & 2.1 & 2 & 126.9 & 117.8 & 138.1 & 6.8 \\
3 & 427.2 & 419.5 & 434.8 & 5.1 & 3 & 176.1 & 166.5 & 181.5 & 5.3 \\
4 & 641.6 & 635.8 & 647.2 & 4.8 & 4 & 111.4 & 102 & 126.8 & 9.6 \\
5 & 798.8 & 795.7 & 801 & 2.5 & 5 & 153.8 & 144.5 & 159.6 & 6.2 \\
\hline
\end{tabular}

Table 3. Numerically evaluated average, minimum, and maximum three types of angular information compared between healthy and infected specimens with standard deviations.

\begin{tabular}{|c|c|c|c|c|c|c|c|c|c|}
\hline \multicolumn{10}{|c|}{ Angle $\left({ }^{\circ}\right)$} \\
\hline \multicolumn{5}{|c|}{ Healthy } & \multicolumn{5}{|c|}{ Infected } \\
\hline \multicolumn{5}{|c|}{ A1 } & \multicolumn{5}{|c|}{ A1 } \\
\hline Number & Avg. & Min. & Max. & StdDev. & Number & Avg. & Min. & Max. & StdDev. \\
\hline 1 & 106.2 & 104.4 & 108.3 & 1.6 & 1 & 137.6 & 124.6 & 147.2 & 8.6 \\
\hline 2 & 93.3 & 92.4 & 95.2 & 1.1 & 2 & 143.4 & 141.2 & 146.6 & 1.9 \\
\hline 3 & 117.9 & 115.1 & 120.7 & 2.3 & 3 & 131.4 & 128.9 & 134.4 & 1.8 \\
\hline 4 & 117.6 & 115.4 & 121.1 & 5.7 & 4 & 131.8 & 127.1 & 135.3 & 2.6 \\
\hline 5 & 110.6 & 110 & 111.4 & 2.9 & 5 & 129.8 & 126.8 & 133.7 & 2.5 \\
\hline \multicolumn{5}{|c|}{ A2 } & \multicolumn{5}{|c|}{ A2 } \\
\hline Number & Avg. & Min. & Max. & StdDev. & Number & Avg. & Min. & Max. & StdDev. \\
\hline 1 & 80.3 & 77.7 & 83.4 & 2.3 & 1 & 93.3 & 89.8 & 98.2 & 3.3 \\
\hline 2 & 92.5 & 90.5 & 95.6 & 1.7 & 2 & 112.9 & 112.1 & 114.1 & 0.8 \\
\hline 3 & 86.6 & 85.7 & 88.4 & 1 & 3 & 102.4 & 98.1 & 107.2 & 3.3 \\
\hline 4 & 75.3 & 71.7 & 79.9 & 3 & 4 & 94.4 & 87.3 & 98.8 & 4.1 \\
\hline 5 & 74.6 & 72.6 & 75.5 & 1 & 5 & 97.5 & 93.1 & 100 & 2.4 \\
\hline \multicolumn{5}{|c|}{$\mathrm{A} 3$} & \multicolumn{5}{|c|}{ A3 } \\
\hline Number & Avg. & Min. & Max. & StdDev. & Number & Avg. & Min. & Max. & StdDev. \\
\hline 1 & 112.1 & 110 & 113.4 & 1.2 & 1 & 128 & 123 & 126.6 & 1.3 \\
\hline 2 & 108.9 & 106.2 & 110.2 & 1.4 & 2 & 146.9 & 144.9 & 148.2 & 1.2 \\
\hline 3 & 125.1 & 122.9 & 127.1 & 1.6 & 3 & 148.2 & 141.9 & 155.6 & 4.7 \\
\hline 4 & 109.8 & 107.8 & 112.8 & 2.1 & 4 & 132.5 & 129.5 & 136 & 2.3 \\
\hline 5 & 98.7 & 92.7 & 102.6 & 3.2 & 5 & 136.8 & 134.4 & 140.8 & 2.1 \\
\hline
\end{tabular}

Since Xan-grading bacterial leaf blight is one of the most serious biotic stressors of rice, the earlier the disease occurs, the higher the yield loss. Along with growth of susceptible varieties, yield loss due to bacterial blight can be increased by up to $70 \%$. Since degree of thickness reduction and the change in the angle of leaf surface, which leads to leaf rolling of rice, are important plant phenotypic data for quantitative trait loci (QTL) analysis of plant architecture and associated genes, we determined the pathological features in the interior of the rice leaf by comparing the physiological structural changes based morphological assessments before and after inoculation of the leaf surface. Thus, the most probable morphological changes occur due to mutations can be identified at a more prior incubation stage within a short duration by employing the proposed OCT-image based analysis procedure. According to the literature, the described rice leaf abnormalities have been identified through visual inspection, leaf surface based leaf rolling index measurements, leaf external thickness, and destructive sectioning assessments [52,56-58]. Leaf thickness is measured from the traversed distance across the leaf blade mesophyll, and values from more than twelve locations along the mesophyll layer of each segment are 
averaged using the mean of three replicates as representative. The leaf rolling index is determined by dividing the distance of the cross axis perpendicular to the axis of the rolling leaf midrib. The main drawback of these methods is abnormalities can be identified only at a relative late stage, when treatments are no longer possible. As a non-destructive clarification, OCT-based quantifications were obtained from representative healthy and partially abnormal specimens after inoculation, which can be used for an approximate classification between healthy and abnormal specimens at a relatively early stage. Since the experiment was demonstrated to investigate feasible applicability of OCT to differentiate healthy and abnormal specimens, the precision of the thickness and angular parameters will be enhanced through succeeding field trials based time-resolved measurements based experimental attempts.

\section{Conclusions}

Non-invasively classified accurate morphological and quantitative information have significant advantages in agriculture for diagnostic evaluations of plant diseases. Hence, low coherence interferometry based SS-OCT was employed here to classify the morphological structures of rice leaf specimens as an initial feasibility investigation. Although the work demonstrates an OCT imaging attempt for a different plant specimen resembling existing reports, the conceptual breakthrough of this study is the OCT-based analysis of acute angular characteristics of the external angle between the lower epidermis layer and lower mid-vein, and the internal angle of the lower mid-vein that associates with leaf rolling cytological mechanism, which is potentially beneficial for the pre-identification of leaf tissue necrosis and atrophy along with subsequent investigation of rice leaf morphological properties, such as bulliform cells; aerenchyma, parenchyma and collenchyma layer; and vascular bundle. The examined acute angle information provided a robust comparison between healthy and abnormal leaf specimens, which can be employed for the pre-identification of leaf mutations. Although rice is one of the crops playing an important role in world economy, non-destructive investigations using OCT have not been descriptively reported to date. Therefore, this proposed study for rice leaf specimens based on OCT can be beneficial and lead to new discoveries in agricultural research. The acquired qualitative and quantitative evaluations sufficiently confirm the applicability of OCT as a potential agricultural tool that can be well-utilized for future studies involving leaf growth and plant growth through new technological enhancements.

Author Contributions: Conceptualization, K.-M.K., M.J. and J.K.; validation, B.-J.Y. and M.J.; formal analysis, S.K.; investigation, H.K., S.K. and X.D.; data curation, H.K. and X.D.; writing-original draft preparation, H.K. and R.E.W.; writing —review and editing, B.-J.Y. and R.E.W.; visualization, P.K.; supervision, K.-M.K., M.J. and J.K.

Funding: This study was supported by BK21 Plus project funded by the Ministry of Education, Korea (21A20131600011). This research was supported by the Bio and Medical Technology Development Program of the NRF funded by the Korean government, MSIP (2017M3A9E2065282). This research was supported by the National Research Foundation of Korea (NRF) grant funded by the Korea government, MSIT (No. 2018R1A5A1025137). Basic Science Research Program through the National Research Foundation of Korea (NRF) funded by the Ministry of Education (No. 2018R1D1A1B07043340).

Conflicts of Interest: The authors declare no conflict of interest.

\section{References}

1. Hossain, M.; Fischer, K.J. Rice research for food security and sustainable agricultural development in Asia: Achievements and future challenges. GeoJournal 1995, 35, 286-298. [CrossRef]

2. Barker, R.; Herdt, R.W.; Rose, B. The Rice Economy of Asia; Routledge: Abingdon-on-Thames, UK, 2014.

3. Zou, L.P.; Sun, X.H.; Zhang, Z.G.; Liu, P.; Wu, J.X.; Tian, C.J.; Qiu, J.L.; Lu, T.G. Leaf rolling controlled by the homeodomain leucine zipper class IV gene Roc5 in rice. Plant Physiol. 2011, 156, 1589-1602. [CrossRef]

4. Jane, W.-N.; Chiang, S.-H. Morphology and development of bulliform cells in Arundo formosana Hack. Taiwania 1991, 36, 85-97.

5. Zou, L.; Zhang, Z.; Qi, D.; Peng, M.; Lu, T. Cytological mechanisms of leaf rolling in rice. Crop Sci. 2014, 54, 198-209. [CrossRef] 
6. Smith, K.; Ball, T.; Conen, F.; Dobbie, K.; Massheder, J.; Rey, A. Exchange of greenhouse gases between soil and atmosphere: Interactions of soil physical factors and biological processes. Eur. J. Soil Sci. 2003, 54, 779-791. [CrossRef]

7. Butterbach-Bahl, K.; Papen, H.; Rennenberg, H. Scanning electron microscopy analysis of the aerenchyma in two rice cultivars. Phyton 2000, 40, 43-55.

8. Tilman, D.; Cassman, K.G.; Matson, P.A.; Naylor, R.; Polasky, S. Agricultural sustainability and intensive production practices. Nature 2002, 418, 671. [CrossRef]

9. Rosenzweig, C.; Iglesias, A.; Yang, X.B.; Epstein, P.R.; Chivian, E. Climate change and extreme weather events; implications for food production, plant diseases, and pests. Glob. Chang. Hum. Health 2001, 2, 90-104. [CrossRef]

10. Li, Z.; Paterson, A.H.; Pinson, S.R.; Stansel, J.W. RFLP facilitated analysis of tiller and leaf angles in rice (Oryza sativa L.). Euphytica 1999, 109, 79-84. [CrossRef]

11. Zhao, S.-Q.; Hu, J.; Guo, L.-B.; Qian, Q.; Xue, H.-W. Rice leaf inclination2, a VIN3-like protein, regulates leaf angle through modulating cell division of the collar. Cell Res. 2010, 20, 935. [CrossRef] [PubMed]

12. Lee, Y.K.; Woo, M.-O.; Lee, D.; Lee, G.; Kim, B.; Koh, H.-J. Identification of a novel candidate gene for rolled leaf in rice. Genes Genomics 2016, 38, 1077-1084. [CrossRef]

13. Zhu, Y.; Chen, H.; Fan, J.; Wang, Y.; Li, Y.; Chen, J.; Fan, J.; Yang, S.; Hu, L.; Leung, H. Genetic diversity and disease control in rice. Nature 2000, 406, 718. [CrossRef]

14. Gnanamanickam, S.; Priyadarisini, V.B.; Narayanan, N.; Vasudevan, P.; Kavitha, S. An overview of bacterial blight disease of rice and strategies for its management. Curr. Sci. 1999, 77, 1435-1444.

15. Vasudevan, P.; Kavitha, S.; Priyadarisini, V.B.; Babujee, L.; Gnanamanickam, S.S. Biological Control of Crop Diseases; Marcel Dekker Inc.: New York, NY, USA, 2002; pp. 11-32.

16. Lim, S.; Wong, S.; Yeong, C.; Lee, S.; Goh, C.J. Rapid detection of cymbidium mosaic virus by the polymerase chain reaction (PCR). J. Virol. Methods 1993, 41, 37-46. [CrossRef]

17. Oard, J.H.; Dronavalli, S.J. Rapid isolation of rice and maize DNA for analysis by random-primer PCR. Plant Mol. Biol. Rep. 1992, 10, 236-241. [CrossRef]

18. Tullis, E.J. Histological studies of rice leaves infected with Helminthosporium oryzae. J. Agric. Res. 1935, 50, 81.

19. Williams, M.; Pande, N.; Nair, S.; Mohan, M.; Bennett, J.J.T.; Genetics, A. Restriction fragment length polymorphism analysis of polymerase chain reaction products amplified from mapped loci of rice (Oryza sativa L.) genomic DNA. Theor. Appl. Genet. 1991, 82, 489-498. [CrossRef]

20. Barreiro, P.; Zheng, C.; Sun, D.-W.; Hernández-Sánchez, N.; Perez-Sanchez, J.; Ruiz-Cabello, J. Non-destructive seed detection in mandarins: Comparison of automatic threshold methods in FLASH and COMSPIRA MRIs. Postharvest Biol. Technol. 2008, 47, 189-198. [CrossRef]

21. Van As, H.J. Intact plant MRI for the study of cell water relations, membrane permeability, cell-to-cell and long distance water transport. J. Exp. Bot. 2006, 58, 743-756. [CrossRef]

22. Jahnke, S.; Menzel, M.I.; Van Dusschoten, D.; Roeb, G.W.; Bühler, J.; Minwuyelet, S.; Blümler, P.; Temperton, V.M.; Hombach, T.; Streun, M.J. Combined MRI-PET dissects dynamic changes in plant structures and functions. Plant J. 2009, 59, 634-644. [CrossRef]

23. Bernal, J.; Fankuchen, I.J. X-ray and crystallographic studies of plant virus preparations: I. Introduction and preparation of specimens II. Modes of aggregation of the virus particles. J. Gen. Physiol. 1941, 25, 111. [CrossRef]

24. Hubeau, M.; Steppe, K.J. Plant-PET scans: In vivo mapping of xylem and phloem functioning. Trends Plant Sci. 2015, 20, 676-685. [CrossRef] [PubMed]

25. Truernit, E.; Haseloff, J. A simple way to identify non-viable cells within living plant tissue using confocal microscopy. Plant Methods 2008, 4, 15. [CrossRef]

26. Sridar, S.; Raman, S.; Kumar, R. Nature's design for superhydrophobicity in tropical leaves. Surf. Innov. 2015, 3, 144-150. [CrossRef]

27. Grulkowski, I.; Liu, J.J.; Potsaid, B.; Jayaraman, V.; Lu, C.D.; Jiang, J.; Cable, A.E.; Duker, J.S.; Fujimoto, J.G. Retinal, anterior segment and full eye imaging using ultrahigh speed swept source OCT with vertical-cavity surface emitting lasers. Biomed. Opt. Express 2012, 3, 2733-2751. [CrossRef]

28. Potsaid, B.; Baumann, B.; Huang, D.; Barry, S.; Cable, A.E.; Schuman, J.S.; Duker, J.S.; Fujimoto, J.G. Ultrahigh speed $1050 \mathrm{~nm}$ swept source/Fourier domain OCT retinal and anterior segment imaging at 100,000 to 400,000 axial scans per second. Opt. Express 2010, 18, 20029-20048. [CrossRef] 
29. Shimada, Y.; Nakagawa, H.; Sadr, A.; Wada, I.; Nakajima, M.; Nikaido, T.; Otsuki, M.; Tagami, J.; Sumi, Y.J. Noninvasive cross-sectional imaging of proximal caries using swept-source optical coherence tomography (SS-OCT) in vivo. J. Biophotonics 2014, 7, 506-513. [CrossRef]

30. Shimada, Y.; Sadr, A.; Burrow, M.F.; Tagami, J.; Ozawa, N.; Sumi, Y.J. Validation of swept-source optical coherence tomography (SS-OCT) for the diagnosis of occlusal caries. J. Dent. 2010, 38, 655-665. [CrossRef]

31. Cernat, R.; Tatla, T.S.; Pang, J.; Tadrous, P.J.; Bradu, A.; Dobre, G.; Gelikonov, G.; Gelikonov, V.; Podoleanu, A.G. Dual instrument for in vivo and ex vivo OCT imaging in an ENT department. Biomed. Opt. Express 2012, 3 , 3346-3356. [CrossRef]

32. Kim, K.; Kim, P.; Lee, J.; Kim, S.; Park, S.; Choi, S.H.; Hwang, J.; Lee, J.H.; Lee, H.; Wijesinghe, R.E. Non-destructive identification of weld-boundary and porosity formation during laser transmission welding by using optical coherence tomography. IEEE Access 2018, 6, 76768-76775. [CrossRef]

33. Shirazi, M.F.; Wijesinghe, R.E.; Ravichandran, N.K.; Kim, P.; Jeon, M.; Kim, J. Quality assessment of the optical thin films using line field spectral domain optical coherence tomography. Opt. Lasers Eng. 2018, 110, 47-53. [CrossRef]

34. Wijesinghe, R.E.; Lee, S.-Y.; Ravichandran, N.K.; Shirazi, M.F.; Kim, P.; Jung, H.-Y.; Jeon, M.; Kim, J. Biophotonic approach for the characterization of initial bitter-rot progression on apple specimens using optical coherence tomography assessments. Sci. Rep. 2018, 8, 15816. [CrossRef] [PubMed]

35. Lee, C.; Lee, S.-Y.; Kim, J.-Y.; Jung, H.-Y.; Kim, J. Optical sensing method for screening disease in melon seeds by using optical coherence tomography. Sensors 2011, 11, 9467-9477. [CrossRef] [PubMed]

36. Manattayil, J.; Ravichandran, N.; Wijesinghe, R.; Shirazi, M.; Lee, S.-Y.; Kim, P.; Jung, H.-Y.; Jeon, M.; Kim, J. Non-Destructive Classification of Diversely Stained Capsicum annuum Seed Specimens of Different Cultivars Using Near-Infrared Imaging Based Optical Intensity Detection. Sensors 2018, 18, 2500. [CrossRef] [PubMed]

37. Jeong, H.; Cho, N.H.; Jung, U.; Lee, C.; Kim, J.-Y.; Kim, J. Ultra-fast displaying spectral domain optical Doppler tomography system using a graphics processing unit. Sensors 2012, 12, 6920-6929. [CrossRef]

38. Ravichandran, N.K.; Wijesinghe, R.E.; Shirazi, M.F.; Park, K.; Lee, S.-Y.; Jung, H.-Y.; Jeon, M.; Kim, J. In vivo monitoring on growth and spread of gray leaf spot disease in capsicum annuum leaf using spectral domain optical coherence tomography. J. Spectrosc. 2016, 2016. [CrossRef]

39. Wijesinghe, R.E.; Lee, S.-Y.; Kim, P.; Jung, H.-Y.; Jeon, M.; Kim, J. Optical inspection and morphological analysis of diospyros kaki plant leaves for the detection of circular leaf spot disease. Sensors 2016, 16, 1282. [CrossRef]

40. Wijesinghe, R.E.H.; Lee, S.-Y.; Kim, P.; Jung, H.-Y.; Jeon, M.; Kim, J. Optical sensing method to analyze germination rate of Capsicum annum seeds treated with growth-promoting chemical compounds using optical coherence tomography. J. Biomed. Opt. 2017, 22, 091502. [CrossRef]

41. Lee, C.-H.; Lee, S.-Y.; Jung, H.-Y.; Kim, J.-H. The application of optical coherence tomography in the diagnosis of Marssonina blotch in apple leaves. J. Opt. Soc. Korea 2012, 16, 133-140. [CrossRef]

42. Wang, K.C.; Astell, C.J.; Wijesinghe, P.; Larcombe, A.N.; Pinniger, G.J.; Zosky, G.R.; Kennedy, B.F.; Berry, L.J.; Sampson, D.D.; James, A.L. Optical coherence tomography-based contact indentation for diaphragm mechanics in a mouse model of transforming growth factor alpha induced lung disease. Sci. Rep. 2017, 7, 1517. [CrossRef]

43. Ravichandran, N.K.; Wijesinghe, R.E.; Shirazi, M.F.; Kim, J.; Jung, H.-Y.; Jeon, M.; Lee, S.-Y. In Vivo Non-Destructive Monitoring of Capsicum Annuum Seed Growth with Diverse $\mathrm{NaCl}$ Concentrations Using Optical Detection Technique. Sensors 2017, 17, 2887. [CrossRef]

44. Ravichandran, N.K.; Wijesinghe, R.E.; Lee, S.-Y.; Shirazi, M.F.; Park, K.; Jung, H.-Y.; Jeon, M.; Kim, J. Swept source optical coherence tomography for in vivo growth monitoring of capsicum annuum seeds treated with different $\mathrm{NaCl}$ concentrations. In Proceedings of the 2017 25th Optical Fiber Sensors Conference, Jeju, Korea, 24-28 April 2017; pp. 1-4.

45. Marques, M.J.; Rivet, S.; Bradu, A.; Podoleanu, A. Complex master-slave for long axial range swept-source optical coherence tomography. OSA Contin. 2018, 1, 1251-1259. [CrossRef]

46. Rivet, S.; Maria, M.; Bradu, A.; Feuchter, T.; Leick, L.; Podoleanu, A. Complex master slave interferometry. Opt. Express 2016, 24, 2885-2904. [CrossRef]

47. Liu, B.; Azimi, E.; Brezinski, M.E. True logarithmic amplification of frequency clock in SS-OCT for calibration. Biomed. Opt. Express 2011, 2, 1769-1777. [CrossRef] 
48. Kim, S.; Wijesinghe, R.; Lee, J.; Shirazi, M.; Kim, P.; Jang, J.; Jeon, M.; Kim, J. Multiple Wavelength Optical Coherence Tomography Assessments for Enhanced Ex Vivo Intra-Cochlear Microstructural Visualization. Electronics 2018, 7, 133. [CrossRef]

49. Evans, D.E. Aerenchyma formation. New Phytol. 2004, 161, 35-49. [CrossRef]

50. Yang, X.; Li, Y.; Ren, B.; Ding, L.; Gao, C.; Shen, Q.; Guo, S. Drought-induced root aerenchyma formation restricts water uptake in rice seedlings supplied with nitrate. Plant Cell Physiol. 2012, 53, 495-504. [CrossRef] [PubMed]

51. Schneider, C.A.; Rasband, W.S.; Eliceiri, K.W. NIH Image to ImageJ: 25 years of image analysis. Nat. Methods 2012, 9, 671. [CrossRef]

52. Hsiao, T.C.; O’Toole, J.C.; Yambao, E.B.; Turner, N.C. Influence of osmotic adjustment on leaf rolling and tissue death in rice (Oryza sativa L.). Plant Physiol. 1984, 75, 338-341. [CrossRef] [PubMed]

53. Cal, A.J.; Sanciangco, M.; Rebolledo, M.C.; Luquet, D.; Torres, R.O.; McNally, K.L.; Henry, A. Leaf morphology, rather than plant water status, underlies genetic variation of rice leaf rolling under drought. Plant Cell Environ. 2019. [CrossRef]

54. Xu, P.; Ali, A.; Han, B.; Wu, X. Current advances in molecular basis and mechanisms regulating leaf morphology in rice. Front. Plant Sci. 2018, 9. [CrossRef]

55. Armstrong, W. A re-examination of the functional significance of aerenchyma. Physiol. Plant. 1972, $27,173-177$. [CrossRef]

56. Zhang, G.-H.; Xu, Q.; Zhu, X.-D.; Qian, Q.; Xue, H.-W. SHALLOT-LIKE1 is a KANADI transcription factor that modulates rice leaf rolling by regulating leaf abaxial cell development. Plant Cell 2009, 21, 719-735. [CrossRef]

57. Lee, Y.-J.; Yang, C.-M.; Chang, K.-W.; Shen, Y. Effects of nitrogen status on leaf anatomy, chlorophyll content and canopy reflectance of paddy rice. Bot. Stud. 2011, 52, 295-303.

58. Turner, N.C.; O’Toole, J.C.; Cruz, R.; Namuco, O.; Ahmad, S. Responses of seven diverse rice cultivars to water deficits I. Stress development, canopy temperature, leaf rolling and growth. Field Crops Res. 1986, 13, 257-271. [CrossRef] 